\title{
Emergency Food Product Packaging by Pectin-Based Antimicrobial Coatings Functionalized by Pomegranate Peel Extracts
}

\author{
Ehsan Ghorbani $\mathbb{D}^{1},{ }^{1}$ Arasb Dabbagh Moghaddam $\left(\mathbb{D},{ }^{1}\right.$ Anousheh Sharifan ${ }^{(D)},{ }^{2}$ \\ and Hossein Kiani $\mathbb{1 D}^{3}$ \\ ${ }^{1}$ Department of Health, Aja University of Medical Sciences, Tehran, Iran \\ ${ }^{2}$ Department of Food Science and Technology, Science and Research Branch, Islamic Azad University, Tehran, Iran \\ ${ }^{3}$ Department of Food Science and Engineering, College of Agriculture and Natural Resources, University of Tehran, Karaj, Iran
}

Correspondence should be addressed to Arasb Dabbagh Moghaddam; admoghaddam2@gmail.com

Received 2 November 2020; Revised 1 January 2021; Accepted 9 January 2021; Published 20 January 2021

Academic Editor: Hadi Hashemi Gahruie

Copyright (c) 2021 Ehsan Ghorbani et al. This is an open access article distributed under the Creative Commons Attribution License, which permits unrestricted use, distribution, and reproduction in any medium, provided the original work is properly cited.

\begin{abstract}
Emergency food products (EFPs) or energy bars are used in critical situations, such as natural disasters, to promote crisis management. EFPs require sophisticated packaging strategies. Edible coatings incorporated with natural antimicrobial agents could be considered as active packaging materials for increasing EFP safety. In this study, pectin-based coatings incorporated with pomegranate peel extracts were used to protect energy bars. Initially, total phenolic contents and antimicrobial and antioxidant properties of aqueous and ethanolic pomegranate peel extracts (PPEs) were determined. Also, PPEs were analyzed by HPLC. In the next step, the extracts were incorporated into the matrix of edible coatings as active substances. The sensory properties and microbial contamination of coated energy bars were investigated during 30 days of storage. Sixteen phenolic substances were detected in the extracts with gallic acid, ellagic acid, caffeic acid, coumaric acid, and quercetin as major ingredients. The ethanolic extract exhibited higher concentrations for all phenolic compounds. The results indicated that the ethanolic extract showed inhibitory effects on S. aureus and E. coli at concentrations of 30 and $50 \mathrm{mg} / \mathrm{ml}$, and the aqueous extract's inhibitory effects were observed at concentrations of 50 and $80 \mathrm{mg} / \mathrm{ml}$, respectively. The antioxidant and antibacterial effects could be attributed to high phenolic content and a combination of different substances. Microbial and sensory tests performed on coated energy bars showed that the active coatings were able to control and reduce the population of microorganisms during storage without adversely affecting sensory properties.
\end{abstract}

\section{Introduction}

Emergency food products (EFPs) or energy bars are known as processed food products specially designed for emergency conditions like natural disasters [1]. Energy bars are also often consumed as nutritious snacks by people who need a quick energy source, such as athletes with high physical activity. Individuals with nutritional problems or irregular meals can also use energy bars for nourishment. Energy bars boost the body's energy level and are often used as a substitute for a meal [2]. The EFP must be safe, nutritionally complete, palatable, easy to use, and easy to distribute [3]. In a crisis, due to nutritional deficiencies and unsuitable hygienic conditions, it is needed to ensure food products' safety. Packaging has an essential role in protecting food products from environmental contamination, extending shelf life, and minimizing food losses [4]. Novel packaging strategies such as the application of active packaging and edible coatings are gaining increasing attention. Currently, food packaging is mainly done using petroleumderived materials. However, studies on alternative materials have been raised to reduce the harmful environmental effects of synthetic materials [5]. 
Edible coatings are defined as thin layers of edible materials on the surface of food products composed of natural biopolymers [6]. Biopolymers can be extracted from natural resources such as agricultural by-products [7]. Pectin is a colloidal carbohydrate in the middle lamellae and primary cell walls of many plants and fruits. Pectin has thickening and emulsifying properties. Pectin-based coatings are appropriate food packaging choices due to their good resistance to oxygen, oil, and aroma and also due to their good mechanical properties $[8,9]$.

Edible packaging may operate as a carrier of functional compounds that improve its functionality [7]. Considerable efforts have been made to enhance available coatings' performance, which increases the shelf life of the food product by delaying oxidation and controlling food-borne pathogens $[4,10]$. The main functions of active coatings in food packaging are releasing active compounds into the surrounding medium or absorption of damaging components such as free radicals, moisture, and oxygen, negatively affecting the product quality [11]. As natural and inexpensive sources of bioactive compounds, plant extracts can be good choices for incorporation into active edible packaging [12]. The pomegranate peel as an agrowaste is an excellent source of bioactive compounds, and pomegranate peel extract (PPE) can be used as an active ingredient in matrix of biobased coatings.

Pomegranate (Punica granatum L.) as a traditional plant is among the first plants cultivated by humans. Scientific confirmation of pomegranate health benefits has led to increased production and consumption in fresh and processed forms since the last century. During pomegranate processing, considerable amounts of pomegranate peels are produced as the major by-products. There are high levels of bioactive compounds in pomegranate peel and its extract, mainly phenolic acids, flavonoids, and hydrolysable tannins. PPE has therapeutic effects such as antioxidant, antimicrobial, anticancer, and anti-inflammatory activities $[13,14]$. Pomegranate peel has higher antioxidant and antimicrobial activity than other parts of the pomegranate fruit $[13,15]$.

Previous studies have demonstrated the positive effects of PPE on food products' shelf life because of its antioxidant and antibacterial properties [16-18].

Qin et al. [12], evaluated the antimicrobial activity of active chitosan films containing PPE. The results demonstrated that $10 \mathrm{~g} / \mathrm{l}$ incorporation of PPE has significant inhibitory effects on S. aureus [12]. Kanatt et al. [5] reported that active films from chitosan and polyvinyl-alcohol containing aqueous PPE increased protection against UV light. Active films containing pomegranate extract reduced the number of $S$. aureus by $2 \log$ cycles and inhibited the growth of B. cereus. Tarkhasi [19] used active edible coating containing PPE for extending the shelf life of silver carp fish. The results confirmed that 5\% PPE addition into the coating matrix considerably reduced the total viable count of bacteria and delayed lipid oxidation.

As a novel approach to extend the shelf life of food products, active edible coatings have gained remarkable attention in recent years because of their advantages compared to conventional packaging. A review of previous studies showed that no research had been done on the use of active coatings for emergency food product packaging, and the present study aims to open a window in this field. According to the nature and application of EFPs, active edible coatings can increase their shelf life and improve the health and physical function of consumers at the same time. Some compounds with high nutritional value are sensitive to various factors, including the process of production. Edible coating matrices have protective and carrier functions for these compounds. The present study introduces a new strategy for the enrichment of emergency food products with sensitive compounds with high nutritional value. The present research intended to study the potential of using active edible coating functionalized by pomegranate peel extract for safety improvement of EFPs. The main purpose of this study was to investigate the antimicrobial/antioxidant properties of aqueous and ethanolic PPEs as well as their effectiveness in active coating composition on microbial contamination of EFPs by considering the sensory properties.

\section{Materials and Methods}

2.1. Materials. Mature and healthy pomegranates (Shirin Pust Ghermez variety) with uniform size and appearance were collected from Saveh, Markazi Province, Iran. Fully ripened fruits with waxy (shiny/reddish) skin were selected (total soluble solids $=13.82 \pm 1.59{ }^{\circ} \mathrm{Brix} / \mathrm{pH}=3.42 /$ total acidity $=0.56 \pm 0.12 \mathrm{~g} / 100 \mathrm{~g})$. The fruits were washed and sanitized with sodium hypochlorite in 20 ppm concentration for 15 minutes. Peels separated manually, dried at $60^{\circ} \mathrm{C}$, and powdered by laboratory-scale mill (Moulinex, Type, Dap1, CMMF $8000 \mathrm{~W}$, France). Microbial strains of Escherichia coli O157:H7 (ATCC35218) and Staphylococcus aureus (PTCC1431) were prepared from the Department of Food Science and Technology, University of Tehran, Iran. Microbial culture media and chemicals including sulfuric acid (98\%), 1,1-diphenyl-2-picrylhydrazine (97\%), 2, 2-azinobis3-ethyl-benzothiazoline-6-sulfonic acid (ABTS), dimethyl sulfoxide, ethanol (70\%), methanol, Folin-Ciocalteu reagent, gallic acid, and sodium carbonate were procured from Merck Co. (Germany) and Sigma-Aldrich Co. (USA).

2.2. Pomegranate Peel Extracts. Solvents of deionized water and ethanolic solution $(80 \% \mathrm{v} / \mathrm{v})$ were used for extraction. The powdered pomegranate peels were homogenized with the solvents at the $1: 20$ ratio, and the mixture was kept away from the light and was allowed to stand for $48 \mathrm{~h}$. The supernatant filtration was performed using Whatman No. 41 filter paper after centrifugation at $3500 \mathrm{rpm}$ for $15 \mathrm{~min}$. The filtrate was rota-vaporized at $50^{\circ} \mathrm{C}$, and the concentrates were dried, powdered, and stored in amber bottles in a desiccator $[20,21]$.

\subsection{Antioxidant Activity}

2.3.1. DPPH Radical Scavenging Activity. DPPH radical scavenging activity of PPEs was determined following the method reported by Parseh and Shahablavasani [22]. $1 \mathrm{mg}$ of PPE was added to $4 \mathrm{ml}$ of DPPH ethanol solution $(0.1 \mathrm{mM})$, 
and the solution was shaken vigorously. The mixture was left to stand for $30 \mathrm{~min}$ in the dark medium at room temperature. Then, the absorbance was recorded at $517 \mathrm{~nm}$ to determine the remaining DPPH in the solution. The radical scavenging activity was calculated by the following equation:

DPPH radical scavenging $(\%)=\frac{(\text { Acontrol }- \text { Asample })}{\text { Acontrol }} \times 100$.

2.3.2. ABTS Radical Scavenging Assay. ABTS radical scavenging activity of PPEs was performed according to Malviya et al. [23]. The ABTS radical was generated by mixing $5 \mathrm{ml}$ of ABTS $(7 \mathrm{mM})$ with $88 \mu \mathrm{l}$ of ammonium persulphate $(140 \mathrm{mM})$ and incubating in the dark at $25^{\circ} \mathrm{C}$ for $16 \mathrm{~h}$ (stock solution). The working solution prepared by mixing stock solution and buffered saline ( $\mathrm{pH}$ 7.2 PBS) until the absorbance value at $734 \mathrm{~nm}$ was equal to $0.70 \pm 0.02$. Then, $100 \mu \mathrm{l}$ of PPE was mixed with $3 \mathrm{ml}$ of the ABTS working solution and kept in a dark place for $10 \mathrm{~min}$. The ABTS radical scavenging capacity of the sample was calculated by the following equation:

$$
\text { ABTS radical scavenging }(\%)=\frac{(\text { Acontrol }- \text { Asample })}{\text { Acontrol }} \times 100 \text {. }
$$

2.4. Determination of Total Phenolic Content. The total phenolic contents of PPEs were measured using the Folin-Ciocalteu method with gallic acid as the standard. $0.1 \mathrm{ml}$ of the diluted extract (10-fold diluted with distilled water) was mixed with distilled water $(6 \mathrm{ml})$ and Folin-Ciocalteu reagents $(0.5 \mathrm{ml})$. After 4 minutes, 20\% sodium carbonate $(1.5 \mathrm{ml})$ was added to the solution, and the final volume was adjusted to $10 \mathrm{ml}$ with distilled water. The final mixture was kept in total darkness for $2 \mathrm{~h}$, and the absorbance was measured at $765 \mathrm{~nm}$ using a spectrophotometer (CEILE- 2, UK). Total phenolic contents were calculated using the calibration curve of gallic acid concentration, and the results were expressed as milligrams of gallic acid equivalent (GAE)/g of dry extract. The standard curve of gallic acid solution (50 to $250 \mathrm{mg} / \mathrm{ml})\left(r^{2}=0.99\right)$ was prepared using a similar procedure [22].

\subsection{Analysis of Phenolic Compounds Using HPLC.} High-pressure liquid chromatography (HPLC) equipped with UV detector was employed to determine the phenolic components in the PPEs. A combination of acetonitrile, water, and acetic acid (2\%) was selected as the mobile phase with a flow rate of $0.5 \mathrm{ml} / \mathrm{min}$. The reverse phase $\mathrm{C} 18$ column was the main system to separate the phenolic compounds. The length of the column and the packed particle sizes were $25 \mathrm{~cm}$ and $5 \mu \mathrm{m}$, respectively. Every injection was accomplished with a volume of $20 \mu$ l. To prepare the samples for analysis, $5 \mathrm{ml}$ of the ethanol-HPLC grade was mixed with $5 \mathrm{ml}$ water. Then, $8 \mathrm{ml}$ of the prepared mixture was mixed with $2 \mathrm{ml}$ of $\mathrm{HCl}(1.2 \mathrm{M})$, and $0.5 \mathrm{~g}$ of dried extract was incorporated. After heating, $10 \mathrm{ml}$ of methanol was added to the obtained mixture and centrifuged for $5 \mathrm{~min}$ at the speed of $4000 \mathrm{rpm}$. The filtered transparent fluid was applied for HPLC phenolic determination. For quantification, initially, $0.1 \mathrm{mg}$ of each standard was solved in $1 \mathrm{ml}$ of ethanol-HPLC grade, and the concentrations of $0.005,0.02,0.04,0.06$, and $0.1 \mathrm{mg} / \mathrm{l}$ were prepared. The obtained solutions were injected into the HPLC apparatus to detect and determine the phenolic compositions [24].

2.6. Microbial Strain Activation. S. aureus (PTCC1431) and E. coli O157:H7 (ATCC35218) were refreshed in tripticase soy broth (Merck, Germany) at $37^{\circ} \mathrm{C}$ incubation and inoculated on tripticase soy agar (Merck, Germany) plates for checking the purity.

2.7. Antimicrobial Activity of Extracts. Minimum inhibitory concentration (MIC) and minimum bactericidal concentration (MBC) were determined to assess the antimicrobial properties of extracts. Stock solutions of each PPE $(500 \mathrm{mg} /$ $\mathrm{ml}$ ) were prepared using dimethyl sulfoxide as the solvent. A volume of $0.5 \mathrm{ml}$ from each stock solution and $0.5 \mathrm{ml}$ of tripticase soy broth (TSB) were added to the first tube and serially diluted in the next 10 to 15 tubes containing $0.5 \mathrm{ml}$ of TSB medium. Then, $0.5 \mathrm{ml}$ of $1 / 100$ dilution of 0.5 McFarland bacterial cultures was added to each tube. Controls for culture medium, solvent, testing bacteria, and PPEs were considered. The peel extract concentration showing no bacterial growth and turbidity after $24 \mathrm{~h}$ incubation at $37^{\circ} \mathrm{C}$ was considered as MIC. Aliquots of $100 \mu \mathrm{l}$ from each transparent tube with no turbidity were separately cultured on Mueller Hinton agar plates, and after $24 \mathrm{~h}$ of incubation at $37^{\circ} \mathrm{C}$, the concentration that showed no bacterial growth was recorded as MBC [25].

2.8. Energy Bar Production. Energy bars were produced according to the following procedure in the form of $50 \mathrm{~g}$ solid bars: shortening $(8 \mathrm{~g})$ was melted in an oven at $112^{\circ} \mathrm{C}$ and other ingredients including wheat flour $(25 \mathrm{~g})$, milk powder $(5 \mathrm{~g})$, sugar $(7 \mathrm{~g})$, lecithin $(0.5 \mathrm{~g})$, vanillin $(0.5 \mathrm{~g})$, cocoa powder $(0.5 \mathrm{~g})$, coconut powder $(0.75 \mathrm{~g})$, vitamins/minerals premix $(3.5 \mathrm{~g})$, and salt $(0.2 \mathrm{~g})$ were added to melted shortening and mixed completely and $5 \mathrm{ml}$ of water was added to the mixture. The semisolid mixture was molded in $4.4 \mathrm{~cm} \times 7.6 \mathrm{~cm}$ dimensions using aluminium foil. Finally, the baking process was done in the oven at $150^{\circ} \mathrm{C}$ for $20 \mathrm{~min}$ [26].

2.9. Energy Bar Coating. Pectin $(2 \% \mathrm{w} / \mathrm{w})$ was dissolved in distilled water at $75^{\circ} \mathrm{C}$ under gentle stirring for $15 \mathrm{~min}$, and glycerol $(0.2 \% \mathrm{w} / \mathrm{w})$, as a plasticizer, was added to the solution. The mixture was sterilized and cooled to $40^{\circ} \mathrm{C}$, and then PPEs were added at the tested concentrations $(0,1,1.5$, and $2 \times$ MIC). Energy bars were coated by immersing them into the coating solution (for $3 \mathrm{~min}$ ) and drying with airflow $(1 \mathrm{~h})$. Under the same conditions, sterile distilled water was used as a coating solution for control samples. All the samples were stored at ambient temperature for 30 days [27]. 
2.10. Microbial Analysis of Coated Energy Bars during Storage Time. $10 \mathrm{~g}$ of samples was homogenized with $90 \mathrm{ml}$ of sterile peptone water $(0.1 \%)$ using a Stomacher lab blender. Appropriate dilutions were spread on sterile petri plates containing plate count agar and incubated at $35 \pm 1^{\circ} \mathrm{C}$, for $24 \mathrm{~h}$, for the enumeration of total count of bacteria. Sabouraud dextrose agar medium was used to enumerate total molds and yeasts with 7 days incubation at $25^{\circ} \mathrm{C}$. MacConkey agar was used for coliforms counting, and petri plates were kept at $37^{\circ} \mathrm{C}$ for $24 \mathrm{~h}[26,28-30]$.

2.11. Sensory Evaluation. Hedonic sensory evaluation of energy bars was conducted with 10 trained tasters. Appearance, aroma, taste, texture, and overall acceptance of coated samples were determined and scored on a scale varying from " $5=$ like extremely" to " $1=$ dislike extremely." Samples were coded with three-digit random numbers and presented in white dishes [31].

2.12. Statistical Analysis. Experiments were carried out in triplicate and mean values with standard deviation were reported. Statistical analysis was performed using the SPSS software version 24 (SPSS Inc., Chicago, IL, USA). Homogeneity test was used for all data reported and then mean values were analyzed by one-way ANOVA, followed by Tukey comparison test. Differences were considered significant at $p<0.05$.

\section{Results and Discussion}

3.1. Total Phenolic Contents of Pomegranate Peel Extracts. Total phenolic content of PPE samples is shown in Figure 1. Ethanolic extract, in comparison with aqueous extract, exhibited a higher phenolic content. Our results regarding total phenolic contents are compatible with that reported by Rosas-Burgas et al. [32] and lower than that mentioned by Derakhshan et al. [33] and Sumaiya et al. [34]. There is a direct relationship between phenolic compounds and the antioxidant activity as well as antimicrobial properties [35]. Iranian pomegranate cultivars were investigated for antioxidant activity by Tehranifar et al. [36], and the level of total phenolics was reported from 295.79 to $985.37 \mathrm{mg}$ GAE/ $100 \mathrm{~g}$. The total phenolic content of PPE has been reported equal to $342 \mathrm{mg}$ GAE/g by [37]. It has been reported that differences between the concentrations of phenolic compounds and their antioxidant activities could depend on several factors, such as the part of the fruit, extraction methods, cultivar, stage, and climatic conditions during fruit maturation [38]. The presence and amount of various antioxidant compounds in plant materials, which have different chemical properties and solubility in different solvents, lead to changes in the yield and type of extracted antioxidants [39].

3.2. Phenolic Compound Detection and Quantitation by HPLC. The HPLC diagrams obtained from the analysis of ethanolic and aqueous extracts of pomegranate peel are

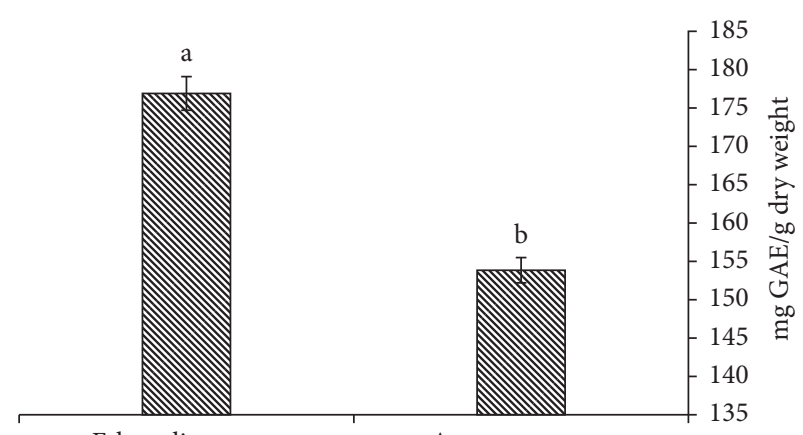

Ethanolic extract

Aqueous extract

Figure 1: Phenolic contents of pomegranate peel extracts. Different letters on the bars indicate significant differences $(p<0.05)$.

shown in Figures 2 and 3, respectively, and diagram analysis data are presented in Table 1. As shown, gallic acid, ellagic acid, and caffeic acid are the most abundant compounds in pomegranate peel extract. The pomegranate peel has various tannins, flavonoids, alkaloids, and organic acids. Various flavonoids like flavan-3-ol, naringin, luteolin, luteolin 7-Oglucoside, pelargonidin, prodelphinidin, catechin, epicatechin, epigallocatechin-3-gallate, kaempferol, kaempferol-3-O-glucoside, kaempferol-3-O-rhamnoglucoside, quercetin, and rutin are found in PPEs [23]. Hmid et al. [40] studied phenolic compounds of eighteen pomegranate cultivars in Morocco. Phenolic compounds were identified as chlorogenic, caffeic, ferulic, gallic, and ellagic acids, catechin, phloridzin, quercetin, epicatechin, and rutin. Mabrouk et al. [37] determined phenolic compounds in PPE. Predominant phenolic compounds were gallic acid $(6041.1 \mu \mathrm{g} / \mathrm{g} \mathrm{dw})$ and caffeic acid $(1220.37 \mu \mathrm{g} / \mathrm{g} \mathrm{dw})$.

According to our results, measured phenolic compounds in PPEs had higher values in the ethanolic extract except galangin. The chemical properties of the solvent and method of extraction lead to differences in the extraction of phenols [41]. The cultivar type, growing region, climate, maturity, and cultural practice strongly influence the chemical composition of pomegranate fruits. Also, significant variations were observed in organic acids, sugars, and phenolic compounds during the years [36].

3.3. Antimicrobial Activity of Extracts. Minimum inhibitory concentration (MIC) is introduced as the lowest concentration of antimicrobial agent with an inhibitory effect on the growth of a certain microorganism, meaning that the microorganism is present in the environment but cannot reproduce. Minimum bactericidal concentration (MBC) is the lowest concentration of the antimicrobial agent, leading to the death of the microorganism, and no living microorganism can survive in a medium containing MBC [22].

Table 2 shows the MIC and MBC of pomegranate peel extracts on E. coli and S. aureus microorganisms. According to the results, at the concentration of $80 \mathrm{mg} / \mathrm{ml}$ of aqueous PPE, 8 colonies of $E$. coli were grown, showing the inhibitory effect against the tested bacteria, and this concentration is introduced as MIC. Also, at the concentrations from 90 to $100 \mathrm{mg} / \mathrm{ml}$, no growth was observed, and the concentration of $90 \mathrm{mg} / \mathrm{ml}$ was 


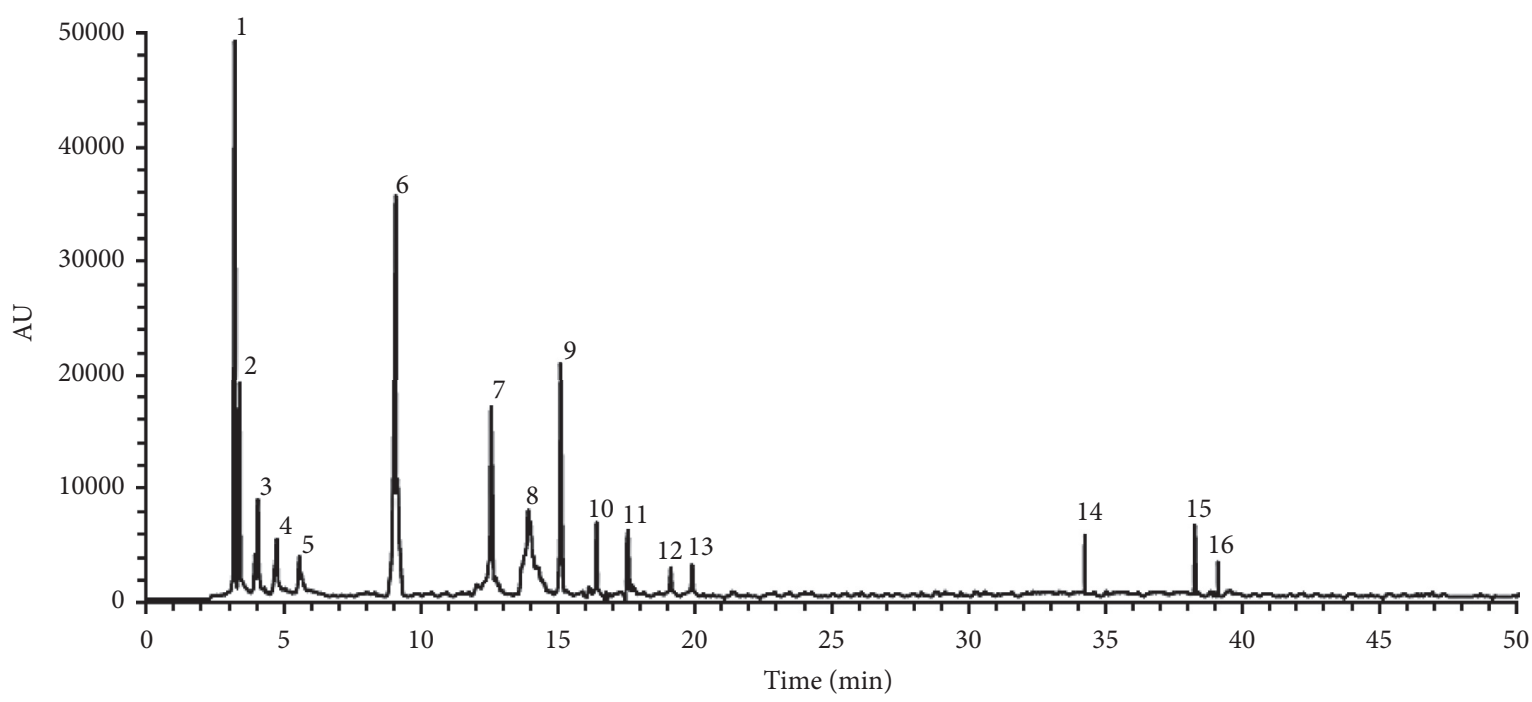

FIGURE 2: HPLC diagram of phenolic compounds of ethanolic extract.

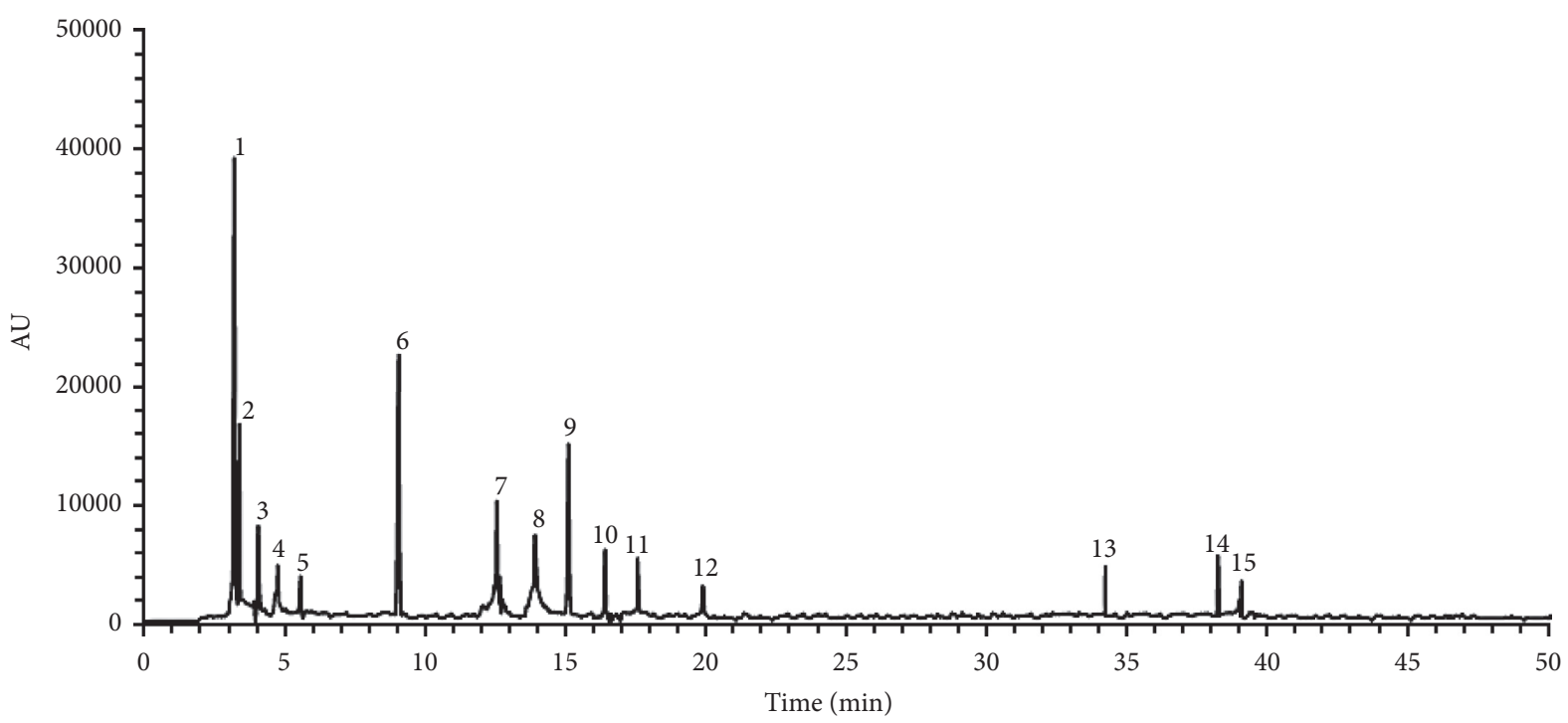

FIGURE 3: HPLC diagram of phenolic compounds of aqueous extract.

introduced as MBC. Concerning S. aureus, MIC was $50 \mathrm{mg} / \mathrm{ml}$, and $\mathrm{MBC}$ was $60 \mathrm{mg} / \mathrm{ml}$. Microbial growth in the presence of ethanolic extract showed that MIC and MBC on E. coli microorganism were at 50 and $60 \mathrm{mg} / \mathrm{ml}$, and regarding S. aureus, they were at 30 and $40 \mathrm{mg} / \mathrm{ml}$, respectively.

Gram-positive bacteria are more susceptible than Gramnegative ones. In agreement with the present study, other studies confirmed that $S$. aureus is more sensitive than $E$. coli to pomegranate extract $[42,43]$. Al-Zoreky et al. [44] confirmed that $S$. aureus was more sensitive than E. coli to PPEs. The outer peptidoglycan layer in Gram-positive bacteria is an ineffective barrier. The phospholipid membrane's impermeability to lipophilic solutes in Gram-negative bacteria leads to resistance to antibacterial substances [45].

Aqueous and ethanolic pomegranate peel extracts were found to have antibacterial activity against different strains of Escherichia coli [46]. Also, the inhibitory effect of pomegranate peel extract on the growth of Staphylococcus aureus has been demonstrated [23]. As the results show, the ethanolic extract has more strong bactericidal and inhibitory effects on tested microorganisms. This finding is in agreement with Ahmad et al. [47] who demonstrated that alcohol has better performance in the extraction of antimicrobial substances compared to water.

The amount of bioactive compounds in different extracts, which depended on regional and variety changes, causes differences in the inhibitory activity of peel extracts [45].

3.4. Antibacterial Effects of Active Coating on Energy Bars during Storage. Antibacterial effects of active coatings incorporated by ethanolic and aqueous PPEs on energy bars are presented in Tables 3 and 4, respectively. Coated energy 
TABLE 1: Phenolic compound concentration in pomegranate peel extracts.

\begin{tabular}{|c|c|c|c|c|}
\hline \multirow{2}{*}{ No. } & \multirow{2}{*}{ Compound } & \multirow{2}{*}{ Retention time (min) } & \multicolumn{2}{|c|}{ Concentration $(\mu \mathrm{g} / \mathrm{ml})$} \\
\hline & & & Aqueous extract & Ethanolic extract \\
\hline 1 & Gallic acid & 3.2 & 529.7740 & 674.9871 \\
\hline 2 & Caffeic acid & 3.4 & 264.8438 & 299.1797 \\
\hline 3 & Catechin & 4.05 & 28.01822 & 30.75171 \\
\hline 4 & Epicatechin & 4.75 & 16.24309 & 26.51934 \\
\hline 5 & Ferulic acid & 5.57 & 14.54545 & 22.36364 \\
\hline 6 & Ellagic acid & 9.05 & 437.5254 & 628.6004 \\
\hline 7 & Quercetin & 12.58 & 154.5000 & 255.2530 \\
\hline 8 & Quercetin-3-methyl-ether & 13.9 & 113.5135 & 148.6486 \\
\hline 9 & Coumaric acid & 15.1 & 172.9885 & 356.3218 \\
\hline 10 & Naringenin & 16.4 & 25.54945 & 28.84615 \\
\hline 11 & Apigenin & 17.55 & 25.31818 & 28.18182 \\
\hline 12 & Kaempferol & 19.1 & ND & 15.15000 \\
\hline 13 & Luteolin & 19.88 & 15.49180 & 15.98361 \\
\hline 14 & Chrysin & 34.2 & 19.83471 & 24.29752 \\
\hline 15 & Pinocembrin & 38.11 & 24.42857 & 28.92857 \\
\hline 16 & Galangin & 39.05 & 14.67123 & 14.38356 \\
\hline
\end{tabular}

*ND: not detected.

TABle 2: Antimicrobial effects of pomegranate peel extracts on S. aureus and E. coli.

\begin{tabular}{lccccccccccccccc}
\hline \multirow{2}{*}{ Type of extract } & \multicolumn{1}{c}{ Type of microorganism } & \multicolumn{11}{c}{ Extract concentration $(\mathrm{mg} / \mathrm{ml})$} \\
& & 5 & 10 & 15 & 20 & 30 & 40 & 50 & 60 & 70 & 80 & 90 & 100 \\
\hline \multirow{2}{*}{ Aqueous } & S. aureus & ++ & ++ & ++ & ++ & ++ & + & 8 colonies & - & - & - & - & - \\
& E. coli & ++ & ++ & ++ & ++ & ++ & ++ & ++ & ++ & + & 8 colonies & - & - \\
\hline \multirow{2}{*}{ Ethanolic } & S. aureus & ++ & ++ & ++ & + & 5 colonies & - & - & - & - & - & - & - \\
& E. coli & ++ & ++ & ++ & ++ & ++ & + & 6 colonies & - & - & - & - & - \\
\hline
\end{tabular}

++ shows the high growth, + indicates low growth, and - indicates lack of growth of microorganism.

TABLE 3: Antibacterial effects of different concentrations of pomegranate peel ethanolic extract incorporated in coatings of emergency food product during 30 days of storage.

\begin{tabular}{|c|c|c|c|c|}
\hline Storage time (days) & Extract concentration $(\times \mathrm{MIC}=50 \mathrm{mg} / \mathrm{ml})$ & Total count & Molds and yeasts & Total coliforms \\
\hline \multirow{4}{*}{1} & 0 & $212.00 \pm 25.09^{\mathrm{dA}}$ & $28.33 \pm 18.33^{\mathrm{aA}}$ & $6.33 \pm 4.16^{\mathrm{aA}}$ \\
\hline & 1 & $120.66 \pm 8.02^{\mathrm{aB}}$ & $2.33 \pm 0.57^{\mathrm{aB}}$ & $0.0 \pm 0.0$ \\
\hline & 1.5 & $96.33 \pm 8.50^{\mathrm{aB}}$ & $0.0 \pm 0.0$ & $0.0 \pm 0.0$ \\
\hline & 2 & $58.66 \pm 4.16^{\mathrm{aC}}$ & $0.0 \pm 0.0$ & $0.0 \pm 0.0$ \\
\hline \multirow{4}{*}{10} & 0 & $310.66 \pm 29.00^{\mathrm{cA}}$ & $15.33 \pm 8.73^{\mathrm{aA}}$ & $6.33 \pm 2.51^{\mathrm{aA}}$ \\
\hline & 1 & $91.66 \pm 9.60^{\mathrm{bB}}$ & $0.0 \pm 0.0$ & $0.0 \pm 0.0$ \\
\hline & 1.5 & $45.00 \pm 8.88^{\mathrm{bC}}$ & $0.0 \pm 0.0$ & $0.0 \pm 0.0$ \\
\hline & 2 & $21.00 \pm 5.29^{\mathrm{bC}}$ & $0.0 \pm 0.0$ & $0.0 \pm 0.0$ \\
\hline \multirow{4}{*}{20} & 0 & $360.66 \pm 27.61^{\mathrm{bA}}$ & $25.00 \pm 8.71^{\mathrm{aA}}$ & $8.33 \pm 2.51^{\mathrm{aA}}$ \\
\hline & 1 & $36.66 \pm 11.93^{\mathrm{cB}}$ & $0.0 \pm 0.0$ & $0.0 \pm 0.0$ \\
\hline & 1.5 & $11.66 \pm 3.05^{\mathrm{cBC}}$ & $0.0 \pm 0.0$ & $0.0 \pm 0.0$ \\
\hline & 2 & $1.66 \pm 1.52^{\mathrm{cC}}$ & $0.0 \pm 0.0$ & $0.0 \pm 0.0$ \\
\hline \multirow{4}{*}{30} & 0 & $435.66 \pm 12.66^{\mathrm{aA}}$ & $43.00 \pm 19.46^{\mathrm{aA}}$ & $9.66 \pm 5.03^{\mathrm{aA}}$ \\
\hline & 1 & $11.33 \pm 7.09^{\mathrm{dB}}$ & $0.0 \pm 0.0$ & $0.0 \pm 0.0$ \\
\hline & 1.5 & $2.33 \pm 0.57^{\mathrm{cC}}$ & $0.0 \pm 0.0$ & $0.0 \pm 0.0$ \\
\hline & 2 & $0.0 \pm 0.0$ & $0.0 \pm 0.0$ & $0.0 \pm 0.0$ \\
\hline
\end{tabular}

${ }^{*}$ Different small letters show significant differences $(p<0.05)$ at certain extract dosage during storage time. ${ }^{*}$ Different capital letters show significant differences $(p<0.05)$ at certain storage time and different extract dosage.

bars had microbial contamination from the first date of storage time. The control coating was not able to reduce bacterial contamination of coliform bacteria, molds, and yeasts. Also, the total count of bacteria was increased during storage time in samples with control coating. While pectin- based active coatings exhibited pronounced antibacterial activity against tested pathogenic strains. However, coated samples with incorporated PPE have shown a reduction in the count of tested bacteria during storage time. So, it can be concluded that active coatings with PPE have inhibitory and 
TABLE 4: Antibacterial effects of different concentrations of pomegranate peel aqueous extract incorporated in coatings of emergency food product during 30 days of storage.

\begin{tabular}{|c|c|c|c|c|}
\hline Storage time (days) & Extract concentration $(\times \mathrm{MIC}=80 \mathrm{mg} / \mathrm{ml})$ & Total count & Molds and yeasts & Total coliforms \\
\hline \multirow{4}{*}{1} & 0 & $212.00 \pm 25.06^{\mathrm{aA}}$ & $28.33 \pm 18.33^{\mathrm{aA}}$ & $6.33 \pm 4.16^{\mathrm{aA}}$ \\
\hline & 1 & $184.33 \pm 48.95^{\mathrm{aA}}$ & $9.00 \pm 8.71^{\mathrm{aA}}$ & $0.33 \pm 0.57^{\mathrm{aB}}$ \\
\hline & 1.5 & $180.67 \pm 21.94^{\mathrm{aA}}$ & $0.0 \pm 0.0$ & $0.0 \pm 0.0$ \\
\hline & 2 & $171.33 \pm 28.57^{\mathrm{aA}}$ & $0.0 \pm 0.0$ & $0.0 \pm 0.0$ \\
\hline \multirow{4}{*}{10} & 0 & $310.67 \pm 29.01^{\mathrm{bA}}$ & $15.33 \pm 8.73^{\mathrm{aA}}$ & $6.33 \pm 2.51^{\mathrm{aA}}$ \\
\hline & 1 & $146.67 \pm 17.95^{\mathrm{aB}}$ & $1.66 \pm 2.88^{\mathrm{aB}}$ & $0.0 \pm 0.0$ \\
\hline & 1.5 & $86.67 \pm 27.74^{\mathrm{bC}}$ & $0.0 \pm 0.0$ & $0.0 \pm 0.0$ \\
\hline & 2 & $13.00 \pm 9.54^{\mathrm{bD}}$ & $0.0 \pm 0.0$ & $0.0 \pm 0.0$ \\
\hline \multirow{4}{*}{20} & 0 & $360.67 \pm 27.61^{\mathrm{cA}}$ & $25.00 \pm 8.71^{\mathrm{aA}}$ & $8.33 \pm 2.51^{\mathrm{aA}}$ \\
\hline & 1 & $145.33 \pm 18.23^{\mathrm{aB}}$ & $0.0 \pm 0.0$ & $0.0 \pm 0.0$ \\
\hline & 1.5 & $15.00 \pm 5.00^{\mathrm{cC}}$ & $0.0 \pm 0.0$ & $0.0 \pm 0.0$ \\
\hline & 2 & $3.67 \pm 6.35^{\mathrm{bD}}$ & $0.0 \pm 0.0$ & $0.0 \pm 0.0$ \\
\hline \multirow{4}{*}{30} & 0 & $435.66 \pm 12.66^{\mathrm{dA}}$ & $43.00 \pm 19.46^{\mathrm{aA}}$ & $9.66 \pm 5.03^{\mathrm{aA}}$ \\
\hline & 1 & $64.67 \pm 30.24^{\mathrm{bB}}$ & $0.0 \pm 0.0$ & $0.0 \pm 0.0$ \\
\hline & 1.5 & $0.0 \pm 0.0$ & $0.0 \pm 0.0$ & $0.0 \pm 0.0$ \\
\hline & 2 & $0.0 \pm 0.0$ & $0.0 \pm 0.0$ & $0.0 \pm 0.0$ \\
\hline
\end{tabular}

${ }^{*}$ Different small letters show significant differences $(p<0.05)$ at certain extract dosage during storage time. ${ }^{*}$ Different capital letters show significant differences $(p<0.05)$ at certain storage time and different extract dosage.

bactericidal effects, in a way that using $100 \mathrm{mg} / \mathrm{ml}$ ethanolic extract or $160 \mathrm{mg} / \mathrm{ml}$ aqueous extract incorporated in coating solution caused to complete inactivation of bacteria in energy bars during 30 days of storage. Edible coatings can prevent microbial growth by limiting their growth requirements, including oxygen, carbon dioxide, and moisture permeability. Also, active coatings suppress the growth of microorganisms by the gradual release of embedded antimicrobial agents onto the food surface, maintaining their critical concentrations over time [48]. Antimicrobial agents increase the shelf life of food products by increasing the lag phase and slowing the growth phase of microorganisms [49]. Due to the thermal processes in the production of energy bars, it can be assumed that the contamination is of the surface contamination type. The presence of active compounds, their gradual release, and the resulting limitations of the coating on the surface of energy bars can limit the growth of surface microorganisms.

Earlier studies have demonstrated the antibacterial activity of pomegranate peels $[44,50,51]$. The presence of broad spectrum antimicrobial compounds in pomegranate peel extract leads to inhibitory effects against Gram-positive and Gram-negative bacteria [23]. Antibacterial action of PPE is attributed to the phenolic toxicity that interacts with sulfhydryl groups of proteins in microorganisms [52]. The antimicrobial activity of phenolic compounds depends on their ability to damage and disrupt cell membrane integrity [53]. It has been concluded that pomegranate peel can be used as a natural preservative for food products [37].

3.5. Antioxidant Activity of Extracts. A single method alone cannot accurately measure the antioxidant potential of food systems, and therefore, several methods are used for this purpose. In this study, DPPH and ABTS scavenging activity assays were used for antioxidant activity determination.

The antioxidant activity characteristics of PPEs are shown in Figure 4. The DPPH scavenging activity of PPEs was reported in the range of $77.02 \%$ to $86.36 \%$ by Orak et al. [54]. Malviya et al. [23] reported that the highest DPPH inhibition activity of PPE was equal to $79.5 \pm 6.5 \%$.

ABTS scavenging activity of ethanolic PPEs in previous studies was equal to $78.92 \pm 1.13 \%$ [55] and $94.6 \pm 6.10 \%$ [23].

The results suggest that the ethanolic extract has more antioxidant activity that can be explained by more total phenolic contents and their action as reducing agents, hydrogen donors, and singlet oxygen quenchers [56]. The nature of the solvent has a significant impact on the extraction capacity of phenolic compounds from plant materials [57]. Ethanolic solvent was found more efficient than water for phenolic compound extraction [58]. Organic solvents have better efficiency as compared to water for antioxidant extraction. Also, the extracts obtained from the mixture of solvents exhibited higher antioxidant activity compared to individual solvents [23].

3.6. Sensory Evaluation. Tables 5 and 6 present the scores given by the panelists to the energy bars, for sensorial preference. No significant differences $(p<0.05)$ were observed among the formulations for any of the attributes evaluated. Samples with active coating received the higher averages for appearance and texture, whereas other sensory parameters, including taste, aroma, and overall acceptance, were negatively affected. According to results, PPE incorporation in the coating solution for emergency food bar coating can negatively change sensory attributes, but there are no significant differences $(p<0.05)$ between samples and control. 


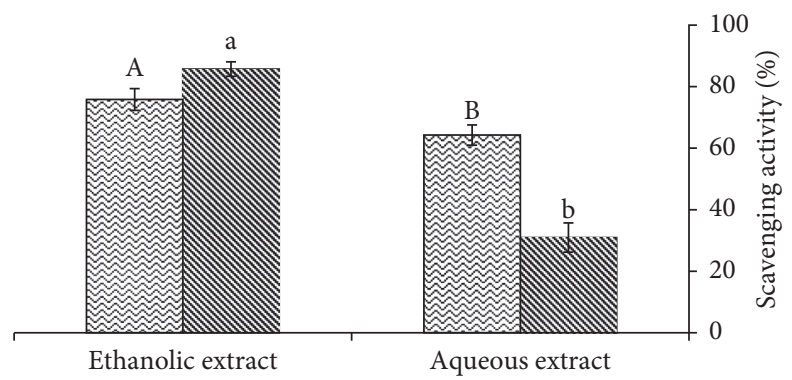

ABTS

D DPPH

FiguRe 4: Radical scavenging activity of pomegranate peel extracts. Different small letters on the bars indicate significant differences $(p<0.05)$ between two extracts. Different capital letters on the bars indicate significant differences $(p<0.05)$ between two extracts.

TABLE 5: Sensory evaluation of the emergency food products coated with different concentrations of ethanolic pomegranate peel extract incorporation.

\begin{tabular}{lccccc}
\hline Extract concentration $(\times \mathrm{MIC}=50 \mathrm{mg} / \mathrm{ml})$ & Appearance & Aroma & Taste & Texture & Overall acceptance \\
\hline 0 & $4.4 \pm 0.54$ & $5.0 \pm 0.00$ & $4.4 \pm 0.54$ & $5.0 \pm 0.00$ & $4.0 \pm 0.70$ \\
1 & $4.8 \pm 0.44$ & $4.6 \pm 0.54$ & $4.6 \pm 0.54$ & $5.0 \pm 0.00$ & $4.6 \pm 0.54$ \\
1.5 & $5.0 \pm 0.00$ & $4.2 \pm 0.44$ & $4.2 \pm 0.44$ & $5.0 \pm 0.00$ & $3.8 \pm 0.83$ \\
2 & $5.0 \pm 0.00$ & $4.4 \pm 0.54$ & $3.8 \pm 0.44$ & $5.0 \pm 0.00$ & $3.6 \pm 0.54$ \\
\hline
\end{tabular}

*No observed significant differences between the averages $(p<0.05)$.

TABLE 6: Sensory evaluation of the emergency food products coated with different concentrations of aqueous pomegranate peel extract incorporation.

\begin{tabular}{lccccc}
\hline Extract concentration $(\times \mathrm{MIC}=80 \mathrm{mg} / \mathrm{ml})$ & Appearance & Aroma & Taste & Texture & Overall acceptance \\
\hline 0 & $4.4 \pm 0.54$ & $5.0 \pm 0.00$ & $4.4 \pm 0.54$ & $4.8 \pm 0.44$ & $4.0 \pm 0.70$ \\
1 & $4.4 \pm 0.54$ & $4.4 \pm 0.54$ & $3.6 \pm 0.54$ & $4.8 \pm 0.44$ & $4.2 \pm 0.83$ \\
1.5 & $4.8 \pm 0.44$ & $4.6 \pm 0.54$ & $4.6 \pm 0.54$ & $4.8 \pm 0.44$ & $4.4 \pm 0.54$ \\
2 & $5.0 \pm 0.00$ & $4.8 \pm 0.44$ & $4.6 \pm 0.54$ & $5.0 \pm 0.00$ & $3.6 \pm 0.54$ \\
\hline
\end{tabular}

*No observed significant differences between the averages $(p<0.05)$.

\section{Conclusions}

Overall, the results showed that the ethanolic extract of pomegranate peel had higher amounts of bioactive compounds as well as higher antioxidant and antibacterial activity. Gallic acid, ellagic acid, and caffeic acid were the most abundant phenolic compounds in pomegranate peel extracts. Pomegranate peel extracts exhibited inhibitory and bactericidal effects against Gram-positive and Gram-negative bacteria. Pectin-based active coating functionalized by PPEs showed good antimicrobial properties and extended the shelf life of energy bars. PPE incorporation in the coating solution slightly affected the sensory properties of samples, but there were no significant differences $(p<0.05)$ compared to the control sample. In summary, the application of active coatings containing pomegranate peel extract at a concentration of $2 \times$ MIC could eliminate pathogenic microorganisms in energy bars within 30 days of storage.

\section{Data Availability}

The data used to support the findings of this study are included within the article.

\section{Conflicts of Interest}

The authors declare that they have no conflicts of interest.

\section{Acknowledgments}

The authors would like to acknowledge the financial support provided by Aja University of Medical Sciences, Iran.

\section{References}

[1] B. Zoumas, L. Armstrong, J. R. Backstrand et al., "High-energy, nutrient-dense emergency relief product," Food and Nutrition Board: Institute of Medicine, National Academy Press, Washington DC, 2002.

[2] A. Gill and A. K. Singh, "Energy bars: quick, healthy and wholesome snack for adolescents," Traditional Lifestyle and Adolescents, EARDA, Delhi, 2020.

[3] E. Sheibani, A. Dabbagh Moghaddam, A. Sharifan, and Z. Afshari, "Linear programming: an alternative approach for developing formulations for emergency food products," Journal of the Science of Food and Agriculture, vol. 98, no. 4, pp. 1444-1452, 2018. 
[4] J.-W. Han, L. Ruiz-Garcia, J.-P. Qian, and X.-T. Yang, "Food packaging: a comprehensive review and future trends," Comprehensive Reviews in Food Science and Food Safety, vol. 17, no. 4, pp. 860-877, 2018.

[5] S. R. Kanatt, M. S. Rao, S. P. Chawla, and A. Sharma, "Active chitosan-polyvinyl alcohol films with natural extracts," Food Hydrocolloids, vol. 29, no. 2, pp. 290-297, 2012.

[6] R. K. Sadrabad, "Advances in edible coatings for fresh fruits and vegetables: a review," Critical Reviews in Food Science and Nutrition, vol. 53, no. 5, pp. 435-450, 2013.

[7] S. Salmieri and M. Lacroix, "Physicochemical properties of alginate/polycaprolactone-based films containing essential oils," Journal of Agricultural and Food Chemistry, vol. 54, no. 26, pp. 10205-10214, 2006.

[8] B. Gazme, A. Madadlou, and S. Moini, "Micron and submicron-sized whey protein-pectin aggregates generated via alkali-catalyzed chemical crosslinking," Journal of Dispersion Science and Technology, vol. 36, no. 1, pp. 154-159, 2015.

[9] A. Valdés, N. Burgos, A. Jiménez, and M. Garrigós, "Natural pectin polysaccharides as edible coatings," Coatings, vol. 5, no. 4, pp. 865-886, 2015.

[10] C. Menzel, C. González-Martínez, F. Vilaplana, G. Diretto, and A. Chiralt, "Incorporation of natural antioxidants from rice straw into renewable starch films," International Journal of Biological Macromolecules, vol. 146, pp. 976-986, 2020.

[11] M. Wrona, K. Bentayeb, and C. Nerín, "A novel active packaging for extending the shelf-life of fresh mushrooms (Agaricus bisporus)," Food Control, vol. 54, pp. 200-207, 2015.

[12] Y.-Y. Qin, Z.-H. Zhang, L. Li, M.-L. Yuan, J. Fan, and T.-R. Zhao, "Physio-mechanical properties of an active chitosan film incorporated with montmorillonite and natural antioxidants extracted from pomegranate rind," Journal of Food Science and Technology, vol. 52, no. 3, pp. 1471-1479, 2015.

[13] J. Huang, C. Liao, X. Ouyang, I. Kahramanoğlu, Y. Gan, and M. Li, "Antimicrobial activity of pomegranate peel and its applications on food preservation," Journal of Food Quality, vol. 2020, Article ID 8850339, 8 pages, 2020.

[14] N. Özreçberoğlu and İ. Kahramanoğlu, "Mathematical models for the estimation of leaf chlorophyll content based on RGB colours of contact imaging with smartphones: a pomegranate example," Folia Horticulturae, vol. 32, no. 1, 2020.

[15] N. Kumar, "Functional properties of pomegranate (punica granatum L.)," Pomegranate, vol. 83, p. 172, 2018.

[16] P. Chen, F. Bakhshi Kazaj, M. Barzegar, and H. Ahmadi Gavlighi, "Production of functional sausage using pomegranate peel and pistachio green hull extracts as natural preservatives," Journal of Agricultural Science and Technology, vol. 22, no. 1, pp. 159-172, 2020.

[17] A. E. El-Hadary and M. Taha, "Pomegranate peel methanolicextract improves the shelf-life of edible-oils under accelerated oxidation conditions," Food Science \& Nutrition, vol. 8, no. 4, pp. 1798-1811, 2020.

[18] S. R. Kanatt, R. Chander, and A. Sharma, "Antioxidant and antimicrobial activity of pomegranate peel extract improves the shelf life of chicken products," International Journal of Food Science \& Technology, vol. 45, no. 2, pp. 216-222, 2010.

[19] A. Tarkhasi, "Effect of edible coating containing pomegranate peel extract on quality and shelf life of silver carp (Hypophthalmichthys molitrix) fillet during refrigerated storage," J Food Ind Microbiol, vol. 2, no. 112, p. 2, 2016.

[20] Y. Li, C. Guo, J. Yang, J. Wei, J. Xu, and S. Cheng, "Evaluation of antioxidant properties of pomegranate peel extract in comparison with pomegranate pulp extract," Food Chemistry, vol. 96, no. 2, pp. 254-260, 2006.

[21] L. B. Hettiarachchy, A. Monteiro, J. Mikcha et al., "Evaluation of antioxidant and antimicrobial capacity of pomegranate peel extract (Punica granatuml.) under different drying temperatures," Chemical Engineering Transactions, vol. 44, pp. 121126, 2015.

[22] H. Parse and A. Shahablavasani, "Comparing total anthocyanins, total phenolics and antioxidant activities of extracts (aqueous, organic and anthocyanin) obtained from pomegranate (peel, juice, and seed) and antimicrobial activity of peel extracts on the four pathogenic bacteria," Journal of Food and Bioprocess Engineering, vol. 3, no. 1, pp. 9-22, 2019.

[23] S. Malviya, A. Arvind, A. Jha et al., "Antioxidant and antibacterial potential of pomegranate peel extracts," Journal of Food Science and Technology, vol. 51, no. 12, pp. 4132-4137, 2014.

[24] P. Mattila and J. Kumpulainen, "Determination of free and total phenolic acids in plant-derived foods by HPLC with diode-array detection," Journal of Agricultural and Food Chemistry, vol. 50, no. 13, pp. 3660-3667, 2002.

[25] Z. Naziri, H. Rajaian, and R. Firouzi, "Antibacterial effects of iranian native sour and sweet pomegranate (Punica Granatum) peel extracts against various pathogenic bacteria," Iranian Journal of Veterinary Research, vol. 13, no. 4, pp. 282-288, 2012.

[26] A. Dabbagh Moghaddam, A. Akhondzadeh Basti, S. A. Keshavarz et al., "Formulation and prototype development of an emergency ration with long shelf life and evaluation of its sensory and microbial characteristics," EBNESINA, vol. 21, no. 1, pp. 13-19, 2019.

[27] V. Navarro, M. L. Villarreal, G. Rojas, and X. Lozoya, “Antimicrobial evaluation of some plants used in Mexican traditional medicine for the treatment of infectious diseases," Journal of Ethnopharmacology, vol. 53, no. 3, pp. 143-147, 1996.

[28] M. Michalczyk, R. Macura, I. Tesarowicz, and J. Banaś, “Effect of adding essential oils of coriander (Coriandrum sativum L.) and hyssop (Hyssopus officinalis L.) on the shelf life of ground beef," Meat Science, vol. 90, no. 3, pp. 842-850, 2012.

[29] B. Ouattara, S. Sabato, and M. Lacroix, "Use of gamma-irradiation technology in combination with edible coating to produce shelf-stable foods," Radiation Physics and Chemistry, vol. 63, no. 3-6, pp. 305-310, 2002.

[30] S.-M. Syne, A. Ramsubhag, and A. A. Adesiyun, "Microbiological hazard analysis of ready-to-eat meats processed at a food plant in Trinidad, West Indies," Infection Ecology \& Epidemiology, vol. 3, no. 1, p. 20450, 2013.

[31] M. H. Ertop and M. Hayta, "Optimization of the level of chickpea sourdough and baking powder in cake formulation by response surface methodology: effects on physicochemical, sensory and antioxidant properties," Food Science and Technology Research, vol. 24, no. 4, pp. 697-706, 2018.

[32] E. C. Rosas-Burgos, A. Burgos-Hernández, L. NogueraArtiaga et al., "Antimicrobial activity of pomegranate peel extracts as affected by cultivar," Journal of the Science of Food and Agriculture, vol. 97, no. 3, pp. 802-810, 2017.

[33] Z. Derakhshan, M. Ferrante, M. Tadi et al., "Antioxidant activity and total phenolic content of ethanolic extract of pomegranate peels, juice and seeds," Food and Chemical Toxicology, vol. 114, pp. 108-111, 2018.

[34] K. Sumaiya, M. Jahurul, and W. Zzaman, "Evaluation of biochemical and bioactive properties of native and imported pomegranate (Punica granatum 1.) cultivars found in 
Bangladesh," International Food Research Journal, vol. 25, no. 2, pp. 737-746, 2018.

[35] A. Ghasemzadeh, H. Z. E. Jaafar, and A. Rahmat, "Antioxidant activities, total phenolics and flavonoids content in two varieties of Malaysia young ginger (Zingiber officinale Roscoe)," Molecules, vol. 15, no. 6, pp. 4324-4333, 2010.

[36] A. Tehranifar, M. Zarei, Z. Nemati, B. Esfandiyari, and M. R. Vazifeshenas, "Investigation of physico-chemical properties and antioxidant activity of twenty Iranian pomegranate (Punica granatum L.) cultivars," Scientia Horticulturae, vol. 126, no. 2, pp. 180-185, 2010.

[37] O. M. Mabrouk, O. E.-S. Shaltout, W. A. Amin, T. M. Ezz, and A. M. Zeitoun, "Evaluation of bioactive compounds in pomegranate fruit parts as an attempt for their application as an active edible film," Journal of Biomaterials, vol. 3, no. 1, pp. 7-17, 2019.

[38] E. Shwartz, I. Glazer, I. Bar-Ya'akov et al., "Changes in chemical constituents during the maturation and ripening of two commercially important pomegranate accessions," Food Chemistry, vol. 115, no. 3, pp. 965-973, 2009.

[39] B. Sultana, F. Anwar, and M. Ashraf, "Effect of extraction solvent/technique on the antioxidant activity of selected medicinal plant extracts," Molecules, vol. 14, no. 6, pp. 2167-2180, 2009.

[40] I. Hmid, D. Elothmani, H. Hanine, A. Oukabli, and E. Mehinagic, "Comparative study of phenolic compounds and their antioxidant attributes of eighteen pomegranate (Punica granatum L.) cultivars grown in Morocco," Arabian Journal of Chemistry, vol. 10, pp. S2675-S2684, 2017.

[41] M. Pinelo, M. Rubilar, J. Sineiro, and M. J. Núñez, "Extraction of antioxidant phenolics from almond hulls (Prunus amygdalus) and pine sawdust (Pinus pinaster)," Food Chemistry, vol. 85, no. 2, pp. 267-273, 2004.

[42] J. Eldiasty, M. Hassan, and O. Kamel, "Evaluation of some agricultural waste extracts against mosquito larvae, and some types of microorganisms as insecticidal and antibiotic agents," Egyptian Academic Journal of Biological Sciences, G. Microbiology, vol. 6, no. 1, pp. 1-16, 2014.

[43] A. Sadeghian, A. Ghorbani, A. Mohamadi-Nejad, and H. Rakhshandeh, "Antimicrobial activity of aqueous and methanolic extracts of pomegranate fruit skin," Avicenna Journal of Phytomedicine, vol. 1, no. 2, pp. 67-73, 2011.

[44] N. S. Al-Zoreky, "Antimicrobial activity of pomegranate (Punica granatum L.) fruit peels," International Journal of Food Microbiology, vol. 134, no. 3, pp. 244-248, 2009.

[45] H. H. Oraki, A. Ş. Demirci, and T. Gümüş, "Antibacterial and antifungal activity of pomegranate (Punica granatum L. cv.) peel," Electronic Journal of Environmental, Agricultural \& Food Chemistry, vol. 10, no. 3, 2011.

[46] S. Voravuthikunchai, A. Lortheeranuwat, W. Jeeju, T. Sririrak, S. Phongpaichit, and T. Supawita, "Effective medicinal plants against enterohaemorrhagic Escherichia coli O157:H7," Journal of Ethnopharmacology, vol. 94, no. 1, pp. 49-54, 2004.

[47] I. Ahmad, Z. Mehmood, and F. Mohammad, "Screening of some Indian medicinal plants for their antimicrobial properties," Journal of Ethnopharmacology, vol. 62, no. 2, pp. 183-193, 1998.

[48] H. Aloui and K. Khwaldia, "Natural antimicrobial edible coatings for microbial safety and food quality enhancement," Comprehensive Reviews in Food Science and Food Safety, vol. 15, no. 6, pp. 1080-1103, 2016.

[49] C. E. Realini and B. Marcos, "Active and intelligent packaging systems for a modern society," Meat Science, vol. 98, no. 3, pp. 404-419, 2014.
[50] J. A. Khan and S. Hanee, "Antibacterial properties of Punica granatum peels," International Journal of Applied Biology and Pharmaceutical Technology, vol. 2, no. 3, pp. 23-27, 2011.

[51] P. A. Meléndez and V. A. Capriles, "Antibacterial properties of tropical plants from Puerto Rico," Phytomedicine, vol. 13, no. 4, pp. 272-276, 2006.

[52] A. Ali, Y. Chen, H. Liu et al., "Starch-based antimicrobial films functionalized by pomegranate peel," International Journal of Biological Macromolecules, vol. 129, pp. 1120-1126, 2019.

[53] X. Carrión-Granda, I. Fernández-Pan, J. Rovira, and J. Maté, "Effect of antimicrobial edible coatings and modified atmosphere packaging on the microbiological quality of cold stored hake (Merluccius merluccius) fillets," Journal of Food Quality, vol. 2018, Article ID 6194906, 12 pages, 2018.

[54] H. H. Orak, H. Yagar, and S. S. Isbilir, "Comparison of antioxidant activities of juice, peel, and seed of pomegranate (Punica granatum L.) and inter-relationships with total phenolic, Tannin, anthocyanin, and flavonoid contents," Food Science and Biotechnology, vol. 21, no. 2, pp. 373-387, 2012.

[55] A. KENNAS and H. AMELLAL-CHIBANE, "Comparison of five solvents in the extraction of phenolic antioxidants from pomegranate (Punica Granatum L.) peel," The North African Journal of Food and Nutrition Research, vol. 3, pp. 140-147, 2019.

[56] L.-W. Chang, L.-J. Juang, B.-S. Wang et al., "Antioxidant and antityrosinase activity of mulberry (Morus alba L.) twigs and root bark," Food and Chemical Toxicology, vol. 49, no. 4, pp. 785-790, 2011.

[57] N. Turkmen, F. Sari, and Y. S. Velioglu, "Effects of extraction solvents on concentration and antioxidant activity of black and black mate tea polyphenols determined by ferrous tartrate and Folin-Ciocalteu methods," Food Chemistry, vol. 99, no. 4, pp. 835-841, 2006.

[58] J. Yu, M. Ahmedna, and I. Goktepe, "Effects of processing methods and extraction solvents on concentration and antioxidant activity of peanut skin phenolics," Food Chemistry, vol. 90, no. 1-2, pp. 199-206, 2005. 